This is an Accepted Manuscript of an article published by Taylor \& Francis in Science and Medicine in Football on 13/11/2017, available online: http://www.tandfonline.com/10.1080/24733938.2017.1403036. 


\section{Post-match Sleeping Behavior based on Match Scheduling over a Season in Elite Football Players}

Sandro Carriço ${ }^{\mathrm{a}}$, S. Skorski ${ }^{\mathrm{b}}$, Rob Duffield $^{\mathrm{c}}$, Bruno Mendes ${ }^{\mathrm{a}}$, Francisco Calvete ${ }^{\mathrm{a}}$, Tim Meyer $^{\mathrm{c}}$

${ }^{a}$ Benfica LAB, Sport Lisboa e Benfica, Lisbon, Portugal

${ }^{b}$ Institute of Sport and Preventive Medicine, Saarland University, Saarbruecken, Germany

${ }^{c}$ Sport and Exercise Discipline Group, UTS: Health, University of Technology Sydney, Moore

Park, Sydney, Australia

Corresponding author: $\quad$ Francisco Calvete

Email: fcalvete@slbenfica.pt

Benfica LAB, Sport Lisboa e Benfica, Lisbon, Portugal 


\title{
Post-match Sleeping Behavior based on Match Scheduling over a Season in Elite Football Players
}

\begin{abstract}
Elite football players are exposed to a variety of situational contexts that can interfere with their normal sleep patterns. However, more detailed and objective evidence of the changes in sleep behavior with various match circumstances is lacking. The present study objectively described sleeping patterns following matches of elite players throughout a regular season. Actimetry was used to determine sleeping patterns of twenty-five elite players from one Portuguese First League (Liga NOS) club for at least 3 normal training days (TD) as a baseline and then after various matches, including home (HM), away (AM), day (DM) and night (NM). Actimetry-derived sleep measures included total sleep duration (TSD), sleep onset latency (SOL), sleep efficiency (SE) and wake episode duration (WED). On TD, both TSD (6:36 h) and SE (85\%) were below recommended healthy ranges of $7-8 \mathrm{~h}$ and $>90 \%$, respectively. TSD was even less after NM compared to both TD (-65min) and DM (-65min) $(\mathrm{p}<0.05)$, without differences between DM and TD ( $\mathrm{p}>0.05)$. Additionally, TSD was greater in AM compared to HM (+77min, $\mathrm{p}=0.001)$. Furthermore, within subject variability in TSD was larger compared to between subject and between match variability, supporting the assumption that the specific nuances of match scheduling lead to sleep impairments in elite football players.
\end{abstract}

Word count: 196

Key Words: sleep, recovery, elite soccer, actigraphy 


\section{Introduction}

Sleep is considered an important factor for athletic recovery and performance (Fullagar et al. 2014, Samuels 2009). Despite its importance to the recovery process, recent evidence suggests elite athletes sleep less (Fullagar, et al. 2014, Sargent, Lastella, et al. 2014) than recommendations published by national sleep foundations (7-10 hours). This finding contrasts with suggestions that engagement in exercise has beneficial effects on improved sleeping behavior (Davenne 2009). Indeed, it has been suggested that athletes even possess superior sleep quality and quantity than nonathletic subjects due to the nature of regular training (Porter and Horne 1981, Shapiro et al. 1987). However, increasing evidence suggests that sleep disruption, and ensuing reduction in quantity and quality of sleep, is common in both individual (Sargent, Halson, et al. 2014, Venter 2012) and team sport athletes (Juliff et al. 2015).

Despite limited evidence in elite football, players are assumed to be healthy sleepers on "normal days" (Meyer 2015). Nonetheless, there are a variety of contexts that can interfere with their normal sleep patterns, such as night matches, travel and congested scheduling (Erlacher et al. 2011), suggesting that sleep issues experienced by football players are predominately situational (Fullagar, Skorski, Duffield, Julian, et al. 2016, Juliff, et al. 2015, Sargent, Lastella, et al. 2014). For example, the effect of match kick-off time on sleep and recovery has received some research attention. A recently published paper observed that despite sleep durations within the normal health range (National-Sleep-Foundation 2013) on training days and day matches (concluded before $6 \mathrm{pm}$ ), players slept significantly less and had later bed times after matches with a kick-off after 6 pm (Fullagar, Skorski, et al. 2016). Alongside reduced sleep was a significant reduction in perceptual recovery following these night matches compared to both training days and day matches (Fullagar, Skorski, et al. 2016). Similarly, Fowler et al. (2014) reported significant reductions in 
sleep duration along with an impaired stress-recovery balance on the night of a match in elite footballers. However, other authors have reported no effect of early-evening matches (Roach et al. 2013) or early evening high-intensity training (Robey et al. 2014) on sleep duration and quality in elite junior players. Hence, the difference in findings suggests that the scheduling of kick-off time and the later finish in night matches results in an excessive shift in normal sleeping behavior (i.e time into bed), and poorer sleep outcomes. Thus, objective data supporting the concerns with sleep patterns in footballers following matches, particularly at night or away from home, is needed.

The issue of match scheduling time and location and ensuing post-match sleep behavior remains to be explored in more detail in professional footballers. Reduced sleep following different match play scenarios is of concern for practitioners given the potential for compromised recovery (Skein et al. 2013). Indeed, it has been shown that sleep restriction following exercise can lead to reductions in the recovery of perceptual (Fullagar, Duffield, et al. 2016, Skein, et al. 2013), cognitive (Jarraya et al. 2014) as well as aerobic (Mougin et al. 1991) and anaerobic (Abedelmalek et al. 2013) performance (Fullagar, et al. 2014) - which all contributes to overall football performance. This could have important repercussions for players over the course of a season and/or during phases of congested scheduling where an impairment in sleep may add to an already decreased recovery state from an increase in competitive match load (Romyn et al. 2016). Furthermore, it is noteworthy that descriptive research analysing objective sleep variables (e.g. actigraphy or polysomnography) over many different matches (e.g. throughout a season) in elite football is lacking. Current longitudinal research has mostly reported post-competition sleeping patterns via subjective sleep diaries (Fullagar, Skorski, et al. 2016, Polman et al. 2007), whereas objective sleep measures have only been reported in isolate post-competition nights (Netzer et al. 2001, Shearer et al. 2015). 
Accordingly, the purpose of the present study was two-fold. First to objectively monitor and describe sleeping patterns of elite football players after matches during a competitive season; second to describe the variability in sleeping patterns between these contexts.

\section{Methods}

\section{Participants}

Data was collected from 25 elite male football players (mean \pm standard deviation (SD) age $26.3 \pm 4.7$ years, body mass $80.4 \pm 5.8 \mathrm{~kg}$, height $183.9 \pm 6.1 \mathrm{~cm}$ ) competing in the Portuguese Liga NOS and UEFA Champions League. All measurements were recorded as part of the regular monitoring of the team to which players gave their consent. The study was conducted in accordance with the Declaration of Helsinki and was approved by the local Human Research Ethics Committee (Universidade de Lisboa).

\section{Study Design}

The present study followed a descriptive, observational design. Data collection was obtained throughout the 2015/2016 regular football season (July 2015 - May 2016). Players sleeping patterns were monitored on every night after a match, independent of whether matches were scheduled at home or away as well as night or day. As a comparative baseline, sleep was also monitored for at least 3 normal training days, deemed a day time training session of a normal load during a training week at least $72 \mathrm{~h}$ from a match. A normal training day included one session in the morning (from $9.30 \mathrm{am}-12.30 \mathrm{pm}$ ) with a duration of $75 \pm 22 \mathrm{~min}$ and a training load of 275 $\pm 158 \mathrm{AU}$ (session-RPE). Naps were not recorded, which is recognized as a limitation of the current study. 
Players sleep behavior was monitored using wristband actigraphy (Actiwatch 2, Philips, Amsterdam, Netherlands). Players resided in their own homes except after away matches played as part of the UEFA Champions League (two matches in total), whereby players stayed in a hotel. The majority of the analyzed matches were played within Portugal and the maximum travel duration for the team was around $3.5 \mathrm{hrs}$. As the team only played two Champions League away matches with a longer travel duration (5 and $11 \mathrm{hrs,} \mathrm{respectively)} \mathrm{travel} \mathrm{was} \mathrm{not} \mathrm{included} \mathrm{as} \mathrm{an}$ additional factor in the analysis. Training schedules were set at the discretion of the team coaches and conditioning staff. Matches were scheduled by the Portuguese or the UEFA football organizations. There was no experimental manipulation of the athletes' training schedule or sleep/wake behaviors and the athletes were free to consume training supplements, caffeine or alcohol during the data collection period - as this represents ecologically appropriate contexts. Technical problems and/or player compliance resulted in several missing data points throughout the season, thus at the end of the collection period, actigraphy data sets which had an overall completion rate of $90 \%$ or greater were retained for analyses. To be included in the analysis a data set were also required to include at least three matches for each player. Within these data sets, individual data points were categorized into "training day" (TD; baseline) and match days (MD). Furthermore match data points were further categorized as "day matches" (DM; matches with kick-off before 6 pm at night), "night matches" (NM; matches which kick-off after 6 pm at night), "home matches" (HM; matches concluded in the home stadium) and "away matches" (AM; matches played away from the home stadium). Regarding the away matches it is noteworthy that players always resided at home after an away match in the Liga NOS instead of staying in the hotel for an additional night due to the short distances the team had to cover $(<4 \mathrm{hrs}$ ). From the 25 
players originally included in the study, 20 were retained for final analyses. From these 20 players 95 training and 154 match observations (home: $\mathrm{n}=75$, away: $\mathrm{n}=79$, day: $\mathrm{n}=38$, night: $\mathrm{n}=116$ ) included for analysis.

\section{Study procedure}

Players were instructed to wear the actigraph unit (weighing $16 \mathrm{~g}$ with band) on their nondominant wrist and only remove it during training sessions and matches. The data was stored on 1-min epochs based on activity counts from a solid state piezo-electric accelerometer with a sampling rate of 32Hz. Data was analysed using the manufacturer's software (Philips Respironics Actiwatch Software). Objective sleep measures included total sleep duration (TSD; total amount of sleep obtained; h:min), sleep onset latency (SOL; time at which bed was entered to when the individual first fell asleep; min), sleep efficiency (SE; sleep time expressed as a \% of time in bed; $\%$ ) and wake episode duration (WED; h:min). It is recognized that polysomnography (PSG) is the most accurate method to quantify sleep; however, PSG might interfere with players' regular sleep since they are not familiar with this method. Thus, given the field-based descriptive nature of the current study, actigraphy was used for this investigation. In this regard, validation studies comparing wrist activity monitors with PSG report high correlations for sleep duration (i.e. $r=$ 0.74) and moderate correlations for wake time within sleep (i.e. $r=0.33$ ) (Alsaadi et al. 2014). Actigraphy data was posteriorly confirmed by each athlete using an individual report in which they had to check measured rest periods and account for possible inconsistencies, without the further use of sleep diaries.

\section{Statistical analysis}


Data are reported as means and standard deviations (SD). A mixed model analysis was performed to examine differences in sleep indices between normal training days and match days as well as between the different match types (home versus away; day versus night). An $\alpha$-error of $\mathrm{P}<0.05$ was accepted as level of significance for statistical comparisons. Furthermore, changes between matches were analysed with mixed general models. In all analysis type of match was included as a fixed effect, and the random effects were player's identity (between-subject SD), match-by-subject ID interaction (true between-match SD) and the residual (within-subject SD). All statistical analyses were conducted using Statistica software (Version 6, 2002 ed, StatSoft Inc, Tulsa, OK, USA).

Magnitude based inferences were conducted to evaluate the true effects with respect to the smallest worthwhile difference of sleep variables (Hopkins et al. 2009). The smallest worthwhile change was determined by using the default approach of standardization with an appropriate betweensubject SD, here the between-subject SD derived from the linear mixed model (random effect: Subject ID x 0.2). The magnitudes of changes of the resulting effects were assessed using the following scale: $<0.2$ trivial, >0.2 small, >0.6 moderate, >1.2 large (Hopkins, et al. 2009). Where the chance of benefit and harm are both calculated a qualitative descriptor was assigned to the following quantitative chances of effect: 0.5-5.0 \%: very unlikely; 5-25\%: unlikely; 25-75\%: possibly; 75-95 \% likely; 95.0-99.5\%: very likely; > 99.5\%: most likely (Hopkins, et al. 2009). 


\section{Results}

All sleep variables are presented in Table 1, with corresponding mean difference effect sizes and chances of positive and negative effects for TSD, SOL, SE and WED in Table 2.

\section{Training vs. match day}

Bedtime was 124 min later on MD compared to TD, (P < 0.001), whilst awakening time was 55 min earlier for TD compared to MD $(\mathrm{P}<0.001)$. Furthermore, SE was significantly reduced for $\mathrm{MD}$ compared to TD $(-5 \%, \mathrm{P}<0.001)$. No differences were evident for any other sleep variables $(\mathrm{P}>0.05)$. Magnitude based inferences indicate a likely to very likely negative effect for decreased TSD (-62 min) and SE (-5.7\%) as well as increased SOL (+9.4 min) after MD compared to $\mathrm{TD}(\mathrm{ES}=-0.5$ to -1.3 , table 2 ). The between subject $\mathrm{SD}$ for TD vs. MD was $27.5 \%$ for $\mathrm{TSD}$, $13 \%$ for WED, 5.6\% for SOL and 2.9\% for SE. True between match SD ranged from 1.7\% (WED) to $30.2 \%$ (TSD), whereas within subject SD was between $10.0 \%$ (SE) and $122.1 \%$ (TSD).

*****Table 1 near here****

\section{Home vs. away match}

Bedtime was significantly later after AM compared to both TD (+142 min, $\mathrm{P}=0.001)$ and HM (+67 min, $\mathrm{P}=0.001)$. However, awakening time was significantly later after AM compared to both TD (+91 min, $\mathrm{P}=0.002)$ and $\mathrm{HM}(+64 \mathrm{~min}, \mathrm{P}=0.002$, table 1$)$, resulting in a likely positively affected TSD after AM compared to HM (+36min, $d=0.7$, table 2$)$. No significant difference was evident for any other sleep variable $(\mathrm{P}>0.05)$. However, magnitude based inferences indicate a possible to likely negative effect for increased SOL $(+11.8 \mathrm{~min}, \mathrm{~d}=-0.4)$ and WED (+3.4 min, -0.3) for HM, whereas SE was likely higher after AM (+2.9\%, ES = 0.4; table 2). The between subject SD for HM vs. AM was $31.9 \%$ for TSD, 13\% for WED, $5.2 \%$ for SOL and 
$2.9 \%$ for SE. True between match SD ranged from 1.5\% (WED) to $24.8 \%$ (TSD), whereas within subject SD was between $9.9 \%$ (SE) and $122.5 \%$ (TSD). Mean and individual cases are presented in figure 1.

\section{Day vs. night matches}

No difference in bedtime was observed between DM and NM (P > 0.21, table 1), however after both matches players went to bed significantly later compared to TD ( $<<0.05)$. Awaking time was significantly earlier after NM compared to DM (-63 min, $\mathrm{P}=0.05)$, whereas no significant difference was found between $\mathrm{DM}$ and TD $(\mathrm{P}=0.71)$. This resulted in a significant reduction in TSD after NM compared to both TD (-65 min, $\mathrm{P}=0.002)$ and DM (-65 min, $\mathrm{P}<$ 0.001). No significant difference was evident for any other sleep variable ( $\mathrm{P}>0.05)$. Magnitude base inferences indicate a likely to most likely negative effect in TSD (-66 min, ES = -1.0) and SE $(-2.3 \%, \mathrm{ES}=-0.3)$ after NM compared to DM (table 2). Between subject SD for DM and NM was

$32.3 \%$ (TSD), $3.8 \%$ (SOL), $2.7 \%$ (SE) and $12.9 \%$ (WED). True between match SD ranged between $2.3 \%$ (WED) and 32.3\% (TSD), whereas within subject SD was between 9.8\% (SE) and $121.2 \%$ (TSD). Mean and individual cases figure 2. 


\section{Discussion}

The present investigation monitored the sleeping patterns of elite football players throughout the competitive season to determine changes in sleep quantity and quality based on match context. Specifically, the effect of match kick-off time and location on post-match sleep patterns was examined. Of note, night matches induced the greatest reduction in sleep volume compared to training days, though sleep patterns following home matches were not significantly different to normal training days. Further, the large proportion of within-player variability support the notion that situational contexts interfere with the normal sleep patterns of elite football players.

Sleep duration on training, and particularly match days was less than the presumed normal healthy range of 7-10 h (National-Sleep-Foundation 2013). These findings are in contrast to recent reports from elite German and Dutch football players, where sleep durations of almost $9 \mathrm{~h}$ were evident on normal training days (Fullagar, Skorski, et al. 2016). However, the current findings support growing evidence suggesting that elite athletes sleep less than national recommendations (Fullagar, et al. 2014, Sargent, Halson, et al. 2014). Indeed, in a survey of 890 elite South African athletes, the majority reported an average sleep duration between 6 and $8 \mathrm{~h}$ per night (Venter 2012). Leeder et al. (2012) further observed that Olympic athletes slept for a lower mean duration and had poorer sleep quality than non-athletic controls over a period of 4 days. The current study shows bed times on training days to be later than previously reported (Fullagar, Skorski, et al. 2016), which are then exacerbated even more on match days.

Besides reduced sleep duration, low sleep efficiency $(<85 \%)$ as well as long sleep onset latency (> $24 \mathrm{~min}$ ) and wake episode durations (> $29 \mathrm{~min}$ ) were noted - which can indicate poor sleep quality in footballers. Indeed, it has been previously reported that athletes need more time to fall asleep (Juliff, et al. 2015) and show poorer sleep efficiency compared to non-athletic 
counterparts (Leeder, et al. 2012). As shown in the magnitudes of the effects, these variables tended to show some collective impairment after home and night matches. Unfortunately, subjective sleep quality was not assessed in the current study. Thus, more research is required to assess sleeping patterns that could potentially influence recovery in football over longer sampling periods (> 4 weeks), especially during prolonged phases of congested scheduling. According to the current results and previously published findings (Fullagar, Skorski, et al. 2016) sleep in football seems mostly disturbed after night matches, which in some leagues (e.g. Germany, Netherlands) might be rather rare. However, these night matches often occur during phases of congested scheduling (e.g. during UEFA Champions League), thus an impairment of sleep might be especially crucial for recovery. Furthermore, for an appropriate assessment of sleep in athletes it is vital to consider other circumstances of their daily life (e.g. job, university), particularly given not all sports are professional and allow for full-time employment.

An important finding of the current study was the consistent reduction in total sleep duration and later bedtime following night matches compared to both normal training days and day matches. This is in accordance with recently published findings by Fullagar et al. (2016) who reported a similar reduction in sleep duration and later bedtimes after night matches in elite German and Dutch football players. The most predictable reason would be the extension of a later bedtime caused by the timing of the match (Fullagar, Skorski, et al. 2016). Accordingly, it is assumed that changes in these sleep variables are likely dependent on relevant situational demands (Juliff, et al. 2015, Sargent, Lastella, et al. 2014). Interestingly, these sleep issues seem not only related to travel demands as the players in the current study did not have to travel more than 3.5 hrs after an away match. In explanation, self-reported reductions in sleep volume and quality are a common occurrence prior to and after a competition in elite athletes (Fullagar, Skorski, et al. 
2016, Juliff, et al. 2015). Pre-competition anxiety can interfere with sleeping patterns and ensuing readiness to perform (Ehrlenspiel et al. 2016, Juliff, et al. 2015), whilst scheduling issues surrounding training and competitions can also alter post-competition sleep (Gupta et al. 2016, Netzer, et al. 2001). Indeed as evidence of this, in the current study within-subject variability was greater compared to between-subject variability in every sleep variable. The high variation in sleep patterns noted within players suggests changes in sleep patterns due to the changes in situational demands, as opposed to variability of sleep between different players. Consequently, the changing match contexts are likely to explain the disruption to 'normal' sleeping patterns in players (i.e.. change of location, kick-off time, travel) (Fullagar, Skorski, et al. 2016).

Sleep duration was significantly longer after away matches compared to home matches. Possible reasons for the longer sleep duration might be that players in the current study almost always slept at home after an away match instead of residing in a hotel for an additional night. Furthermore, training was usually scheduled approximately 1 hour later after an away match compared to home matches. Additionally, it might be speculated that the influence of post-match social activities had a greater influence after a home match since players do not have to travel back home but instead are offered the opportunity to spend more time with family and friends; thus away matches remove these effects due to the requirement to travel home.

Regarding the fact that players in the current study performed $47 \%$ of their games at night the impaired sleep after night matches may present special long-term concerns for practitioners in such an environment. Indeed, sleep restriction following exercise can lead to reductions in the recovery of perceptual performance (Fullagar, Duffield, et al. 2016, Skein, et al. 2013). Although speculative, this could have important repercussions for players over the course of a season where a reduction in sleep quantity may unnecessarily add to an already decreased recovery state from 
an increase in competitive match load (Romyn et al. 2016). Since the large within subject variability supports the assumption that sleep is likely impaired by situational demands (Juliff, et al. 2015) more research is required analysing the interaction between sleep loss and recovery (perceptual and performance) in elite football, especially during congested scheduling and increased match demands (e. g. UEFA Champions League).

One of the limitations of the present study was the inconsistent amount of training and match data per player (95 training vs. 154 match observations). Unfortunately, due to equipment availability it was not possibly to monitor every player on every night throughout the season. Furthermore, the sample size used in this study was relatively low, limiting the significance of the results; however this is not uncommon in studies with professional players. Indeed, it should be acknowledged that all players were first division elite players and monitored throughout a season, making these results very meaningful and transferable into elite football. Another issue is the observational nature of the study. This gives coaches and staff the opportunity to respond to perceived stress, which in turn may increase variability in uncontrollable independent variables. Additionally, perceived sleep quality was not collected in the current study due to organizational restraints.

\section{Conclusions}

The primary findings of this study were the significant reduction in total sleep duration and later bedtime following (night) matches compared to normal training days. To our knowledge, this is the first study analysing actigraphy sleep data throughout a season in professional footballers. Since the majority of previous studies used diaries to evaluate athlete's sleeping patterns over

prolonged periods, the current results add value due to the more objective nature of the 
methodology. Furthermore, within subject variability was larger compared to between subject and between match variability, supporting the assumption that sleep is mostly disrupted by situational

demands. The current results support the assumption that the late bedtime after a late kick-off causes an impairment of sleep duration and quality. However, more research is required to assess if such disruptions of sleeping patterns could potentially influence recovery in football across various scenarios and over longer sampling periods.

\section{Perspectives}

The current study supports increasing evidence that elite athletes sleep less than national recommendations (Sargent, Lastella, et al. 2014) and that competing at night seems to have a consistent effect on sleeping variables in football players. Even though, a sleep hygiene strategy has been unsuccessful in alleviating these issues in an acute scenario (Fullagar, Skorski, Duffield and Meyer 2016) it remains unclear if such interventions might help to better cope with sleep loss after night matches in chronic situations. This is especially true for practitioners working in an elite football environment with many matches played at night. The accumulation of sleep disruption might alter the physiological and perceptual recovery state of the players, especially over the course of an entire season as well as during congested scheduling and increased match demands. Additionally, it is important to understand the intra-individual variability in sleep requirements, which cannot be easily diagnosed so far, as this would include multiple interventions within a single athlete. Indeed, to our knowledge this is the first study analysing the variability of sleep indices within and between players using longitudinal data and a mixed model approach. Future research should focus on the influence of such individual sleep requirements on recovery. 
Interpreting worthwhile changes in sleep and recovery data on the individual level seems to be the most beneficial approach for elite players.

\section{Acknowledgements}

The authors would like to thank all the players for their time and participation. The authors would also like to thank Dr. Andrew Govus for his statistical guidance, as well as Tobias Tröß for his help with the data structuring.

\section{Disclosure statement}

The authors declare that there are no conflicts of interest. 


\section{References}

Abedelmalek S, Chtourou H, Aloui A, Aouichaoui C, Souissi N, Tabka Z. 2013. Effect of time of day and partial sleep deprivation on plasma concentrations of IL-6 during a short-term maximal performance. Eur J Appl Physiol. Jan;113:241-248.

Alsaadi SM, McAuley JH, Hush JM, Bartlett DJ, McKeough ZM, Grunstein RR, Dungan GC, Maher CG. 2014. Assessing Sleep Disturbance in Low Back Pain: The Validity of Portable Instruments. Plos One. Apr 24;9.

Davenne D. 2009. Sleep of athletes - Problems and possible solution. Biol Rhythm Res.40:45-52.

Ehrlenspiel F, Erlacher D, Ziegler M. 2016. Changes in Subjective Sleep Quality Before a Competition and Their Relation to Competitive Anxiety. Behav Sleep Med. Dec 09:1-14.

Erlacher D, Ehrlenspiel F, Adegbesan OA, El-Din HG. 2011. Sleep habits in German athletes before important competitions or games. J Sports Sci. May;29:859-866.

Fowler P, Duffield R, Vaile J. 2014. Effects of domestic air travel on technical and tactical performance and recovery in soccer. Int J Sports Physiol Perform. May;9:378-386.

Fullagar H, Skorski S, Duffield R, Meyer T. 2016. The effect of an acute sleep hygiene strategy following a late-night soccer match on recovery of players. Chronobiol Int.33:490-505.

Fullagar HH, Duffield R, Skorski S, White D, Bloomfield J, Kolling S, Meyer T. 2016. Sleep, Travel, and Recovery Responses of National Footballers During and After Long-Haul International Air Travel. Int J Sports Physiol Perform. Jan;11:86-95.

Fullagar HH, Skorski S, Duffield R, Hammes D, Coutts AJ, Meyer T. 2014. Sleep and Athletic Performance: The Effects of Sleep Loss on Exercise Performance, and Physiological and Cognitive Responses to Exercise. Sports Med. Oct 15. 
Fullagar HH, Skorski S, Duffield R, Julian R, Bartlett J, Meyer T. 2016. Impaired sleep and recovery after night matches in elite football players. J Sports Sci. Jul;34:1333-1339.

Gupta L, Morgan K, Gilchrist S. 2016. Does Elite Sport Degrade Sleep Quality? A Systematic Review. Sports Med. Nov 29.

Hopkins WG, Marshall SW, Batterham AM, Hanin J. 2009. Progressive statistics for studies in sports medicine and exercise science. Med Sci Sports Exerc. Jan;41:3-13.

Jarraya S, Jarraya M, Chtourou H, Souissi N. 2014. Effect of time of day and partial sleep deprivation on the reaction time and the attentional capacities of the handball goalkeeper. Biol Rhythm Res. Mar 4;45:183-191.

Juliff LE, Halson SL, Peiffer JJ. 2015. Understanding sleep disturbance in athletes prior to important competitions. J Sci Med Sport. Jan;18:13-18.

Leeder J, Glaister M, Pizzoferro K, Dawson J, Pedlar C. 2012. Sleep duration and quality in elite athletes measured using wristwatch actigraphy. J Sports Sci.30:541-545.

Meyer T, Wegmann, M., Poppendieck, W., Fullagar, H.H.K. 2015. Regenerative interventions in professional football. Sports Orthop Traumatol.30:112-118.

Mougin F, Simon-Rigaud ML, Davenne D, Renaud A, Garnier A, Kantelip JP, Magnin P. 1991. Effects of sleep disturbances on subsequent physical performance. Eur J Appl Physiol Occup Physiol.63:77-82.

Sleep in America poll: Exercise and sleep. Available from https://sleepfoundation.org/sites/default/files/RPT336 Summary of Findings 0220 2013.pdf

Netzer NC, Kristo D, Steinle H, Lehmann M, Strohl KP. 2001. REM sleep and catecholamine excretion: a study in elite athletes. Eur J Appl Physiol. Jun;84:521-526. 
Polman R, Nicholls AR, Cohen J, Borkoles E. 2007. The influence of game location and outcome on behaviour and mood states among professional rugby league players. J Sports Sci. Nov;25:1491-1500.

Porter JM, Horne JA. 1981. Exercise and sleep behaviour. A questionnaire approach. Ergonomics. Jul;24:511-521.

Roach GD, Schmidt WF, Aughey RJ, Bourdon PC, Soria R, Claros JC, Garvican-Lewis LA, Buchheit M, Simpson BM, Hammond K, et al. 2013. The sleep of elite athletes at sea level and high altitude: a comparison of sea-level natives and high-altitude natives (ISA3600). Br J Sports Med. Dec;47 Suppl 1:i114-120.

Robey E, Dawson B, Halson S, Gregson W, Goodman C, Eastwood P. 2014. Sleep quantity and quality in elite youth soccer players: a pilot study. Eur J Sport Sci.14:410-417.

Romyn G, Robey E, Dimmock JA, Halson SL, Peeling P. 2016. Sleep, anxiety and electronic device use by athletes in the training and competition environments. Eur J Sport Sci.16:301-308.

Samuels C. 2009. Sleep, recovery, and performance: the new frontier in high-performance athletics. Phys Med Rehabil Clin N Am. Feb;20:149-159, ix.

Sargent C, Halson S, Roach GD. 2014. Sleep or swim? Early-morning training severely restricts the amount of sleep obtained by elite swimmers. Eur J Sport Sci.14 Suppl 1:S310-315.

Sargent C, Lastella M, Halson SL, Roach GD. 2014. The impact of training schedules on the sleep and fatigue of elite athletes. Chronobiol Int. Dec;31:1160-1168.

Shapiro CM, Catterall J, Warren P, Oswald I, Trinder J, Paxton S, East BW. 1987. Lean BodyMass and Non-Rapid Eye-Movement Sleep. Brit Med J. Jan 3;294:22-22.

Shearer DA, Jones RM, Kilduff LP, Cook CJ. 2015. Effects of competition on the sleep patterns of elite rugby union players. Eur J Sport Sci.15:681-686. 
Skein M, Duffield R, Minett GM, Snape A, Murphy A. 2013. The effect of overnight sleep deprivation after competitive rugby league matches on postmatch physiological and perceptual recovery. Int J Sports Physiol Perform. Sep;8:556-564.

Venter RE. 2012. Role of sleep in performance and recovery of athletes: a review article. SA J Res Sport Phys Ed Rec.34:167-184. 
Table 1: Actigraphy sleep responses following a normal training day (TD) and match day (MD) as well as differences between home matches (HM), away matches (AM), day matches (DM) and night matches (NM) in elite soccer players throughout a season.

\begin{tabular}{|c|c|c|c|c|c|c|}
\hline & $\begin{array}{c}\text { TD } \\
(n=95)\end{array}$ & $\begin{array}{c}\text { MD } \\
(n=154)\end{array}$ & $\begin{array}{c}\text { HM } \\
(n=75)\end{array}$ & $\begin{array}{c}\mathrm{AM} \\
(\mathrm{n}=79)\end{array}$ & $\begin{array}{c}\text { DM } \\
(n=38)\end{array}$ & $\begin{array}{c}\text { NM } \\
(n=116)\end{array}$ \\
\hline Bedtime & $0: 14 \pm 0: 38$ & $2: 14 \pm 1: 00^{*}$ & $1: 35 \pm 0: 53$ & $2: 37 \pm 1: 39^{* \#}$ & $2: 16 \pm 2: 37^{*}$ & $2: 17 \pm 0: 57^{*}$ \\
\hline Awakening time & $8: 04 \pm 0: 19$ & $9: 03 \pm 0: 53 *$ & $8: 39 \pm 0: 51$ & $9: 35 \pm 1: 19 * \#$ & $9: 04 \pm 1: 08 *$ & $8: 01 \pm 0: 41^{\wedge}$ \\
\hline Time in bed (h:min) & $7: 40 \pm 0: 42$ & $7: 15 \pm 1: 02 *$ & $7: 07 \pm 1: 10$ & $7: 38 \pm 1: 26^{\#}$ & $8: 05 \pm 1: 42 *$ & $6: 55 \pm 1: 36^{* \wedge}$ \\
\hline Total sleep duration (h:min) & $6: 36 \pm 0: 45$ & $5: 49 \pm 0: 43^{*}$ & $5: 33 \pm 0: 53$ & $6: 09 \pm 1: 00$ & $6: 39 \pm 1: 32$ & $5: 28 \pm 1: 28 * \wedge$ \\
\hline Sleep onset latency (min) & $24 \pm 9$ & $32 \pm 17$ & $35 \pm 28$ & $26 \pm 20$ & $41 \pm 42$ & $31 \pm 21$ \\
\hline Sleep efficiency $(\%)$ & $85 \pm 5$ & $79 \pm 6^{*}$ & $78 \pm 7$ & $80 \pm 8$ & $81 \pm 8$ & $78 \pm 8$ \\
\hline Total wake episode duration (min) & $30 \pm 16$ & $31 \pm 12$ & $29 \pm 13$ & $33 \pm 15$ & $33 \pm 17$ & $30 \pm 12$ \\
\hline \multicolumn{7}{|l|}{$\mathrm{n}=$ number of nights } \\
\hline \multicolumn{7}{|c|}{ * Significantly different to TD $(\mathrm{P}<0.05)$} \\
\hline \multicolumn{7}{|c|}{${ }^{\#}$ Significantly different to $\mathrm{HM}(\mathrm{P}<0.05)$} \\
\hline tly different to & $<<0.05)$ & & & & & \\
\hline
\end{tabular}


Table 2: Mean differences and effect sizes for sleep indices between normal training day (TD) and match day (MD) as well as differences between home matches (HM), away matches (AM), day matches (DM) and night matches (NM) in elite soccer players throughout a season.

\begin{tabular}{|c|c|c|c|}
\hline & MD & HM & DM \\
\hline & \multicolumn{3}{|c|}{ Total sleep duration } \\
\hline $\begin{array}{l}\text { Mean difference } \\
\text { (h:min; } \pm 95 \% \mathrm{Cl} \text { ) }\end{array}$ & $-0: 62 \pm 0: 23$ & $-0: 36 \pm 0: 31$ & $-1: 06 \pm 0: 34$ \\
\hline SMD $( \pm 90 \% \mathrm{Cl})$ & $-1.3 \pm 0.5$ & $0.7 \pm 0.6$ & $-1.0 \pm 0.5$ \\
\hline$\%$ changes (+/trivial-) & $0 / 0 / 100$ & $94 / 4 / 2$ & $0 / 0 / 100$ \\
\hline \multirow[t]{2}{*}{ Qualitative descriptor } & Most likely negative & Likely positive & Most likely negative \\
\hline & \multicolumn{3}{|c|}{ Sleep onset latency } \\
\hline $\begin{array}{l}\text { Mean difference } \\
(\mathrm{min} ; \pm 90 \% \mathrm{Cl})\end{array}$ & $-9.4 \pm 8.9$ & $-11.8 \pm 17.5$ & $10.5 \pm 21.5$ \\
\hline SMD $( \pm 90 \% \mathrm{Cl})$ & $-0.5 \pm 0.4$ & $-0.4 \pm 0.6$ & $0.5 \pm 0.9$ \\
\hline$\%$ changes (+/trivial/-) & $2 / 6 / 92$ & $11 / 4 / 85$ & $96 / 2 / 2$ \\
\hline \multirow[t]{2}{*}{ Qualitative descriptor } & Likely negative & Likely negative & Very likely positive \\
\hline & \multicolumn{3}{|c|}{ Sleep efficiency } \\
\hline $\begin{array}{l}\text { Mean difference } \\
(\mathrm{min} ; \pm 90 \% \mathrm{Cl})\end{array}$ & $-5.7 \pm 3.0$ & $2.9 \pm 4.4$ & $-2.3 \pm 4.7$ \\
\hline SMD $( \pm 90 \% \mathrm{Cl})$ & $-1.2 \pm 0.6$ & $0.4 \pm 0.6$ & $-0.3 \pm 0.6$ \\
\hline$\%$ changes (+/trivial/-) & 0/1/99 & $82 / 9 / 9$ & $0 / 0 / 100$ \\
\hline \multirow[t]{2}{*}{ Qualitative descriptor } & Very likely negative & Likely positive & Most likely negative \\
\hline & \multicolumn{3}{|c|}{ Wake episode duration } \\
\hline $\begin{array}{l}\text { Mean difference } \\
(\mathrm{min} ; \pm 90 \% \mathrm{Cl})\end{array}$ & $0.6 \pm 2.3$ & $-3.4 \pm 3.7$ & $2.8 \pm 5.3$ \\
\hline SMD $( \pm 90 \% \mathrm{Cl})$ & $0.04 \pm 0.2$ & $-0.3 \pm 0.3$ & $0.2 \pm 0.4$ \\
\hline$\%$ changes (+/trivial/-) & $6 / 93 / 1$ & $1 / 35 / 65$ & $7 / 91 / 1$ \\
\hline Qualitative descriptor & Likely trivial & Possibly negative & Trivial \\
\hline
\end{tabular}




\section{Figure captions}

Figure 1: Mean (white bars) and individual cases (black dots) of TSD, SOL, SE and WED for training days (left bar), home matches (middle bar) and away matches (right bar).

Figure 2: Mean (white bars) and individual cases (black dots) of TSD, SOL, SE and WED for training days (left bar), day matches (middle bar) and night matches (right bar). 

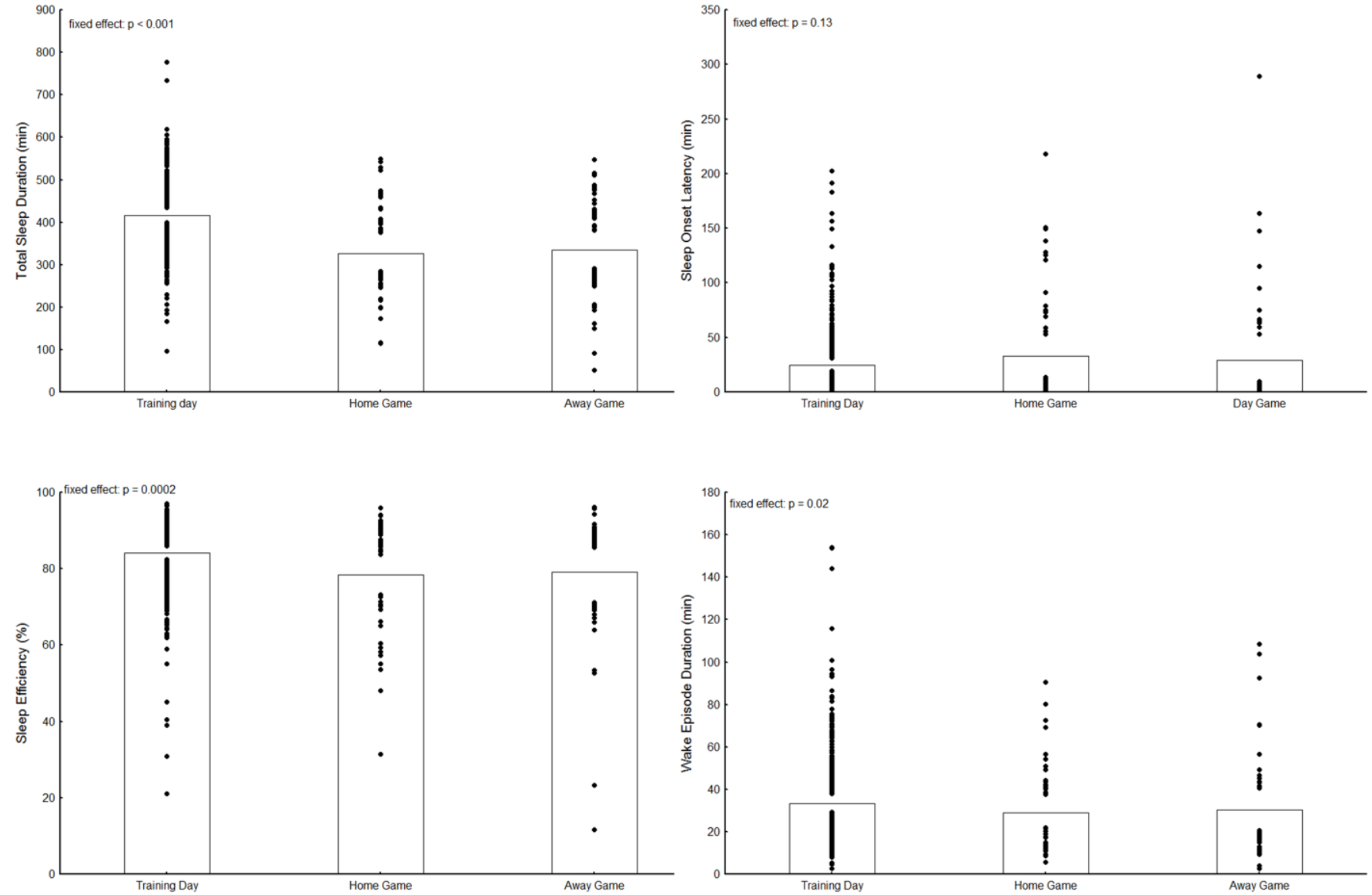

Figure 1 
